\title{
A Modified Halogen Solar Simulator
}

\author{
Julius Tanesab ${ }^{*}, 1$, Muchammad Ali ${ }^{1}$, Gratia Parera ${ }^{1}$, James Mauta ${ }^{1}$, Rusman Sinaga ${ }^{1}$ \\ \{julius_halan@yahoo.co.id, muchammadali123@gmail.com, pareragratia@gmail.com, \\ jamesjosiasmauta@gmail.com,aganis02@yahoo.com\} \\ ${ }^{1}$ Politeknik Negeri Kupang, Jl. Adisucipto, Kupang. Indonesia
}

\begin{abstract}
Many researches on the low-cost solar simulators for PV module performance testing have been carried out. However, it was found that the previous designs require improvements to address the needs of PV module performance test equipment specifically for dust impact experiments. As the dust material attaching on the surface of PV module is removed easily during experiments, module position should be kept to face upwards. This study reported results of a solar simulator developed for testing characteristics of PV modules including those contaminated with dust. Test results showed that the solar simulator worked well. Voltage input and distance of halogen lamps can be adjusted to produce various light intensities received by the examined PV module. Relative difference of maximum power output (Pmax) of an examined PV module exposed to the Sun and the developed solar simulator was about $33 \%$. The large difference was likely contributed to human errors and non-standard equipment applied during the study.
\end{abstract}

Keywords: solar simulator, halogen lamp, PV performance

\section{Introduction}

A sun simulator is a controllable device that provides artificial solar irradiance referring to the standard spectrum i.e. air mass 1.5 used for the testing of solar cells [1]. By deploying a solar simulator, some disadvantages of natural sunlight-based experiment such as unstable weather conditions and low reproducibility of measurements can be addressed. Nevertheless, artificial light produced by a solar simulator is not precisely similar to solar irradiance. It still shares some defects when input voltages are changed, as a result the spectrum and the distribution of light intensity are not uniform over the available collector test area [2].

Halogen is a type of lamps that has been widely applied as a solar simulator light source [1-4]. In addition to its low price, the use of the type of the lamp is based on its characteristics which shares similar spectrum to sunlight [5]. Material of the filament of halogen is different to other type of lamps, it contains specific gas to increase light intensity and service life $[6,7]$.

Grandi et al [8] in a research investigated the performance of a solar simulator using hybrid light emitting diodes and halogens. Results of the experiments applying three different light guidelines showed that the simulator unit can achieve a Class $\mathrm{C}$ uniformity over an area of $10 \times 10 \mathrm{~cm}$. The estimated total cost of the proposed solar simulator module was around 250 $€$, including the cost of lamps as much as $115 €$. 
Salam et al [9] designed and explored a laboratory-scale solar simulator for a university. The solar simulator was built from halogen lamps as the light source. The research was focused on the effects of temperature of halogen lamps which usually heat up quickly. The development of this solar simulator was then tested to obtain the characteristics of current and voltage of a $3 \mathrm{~W}$ and a $5 \mathrm{~W}$ PV module. The test results showed the current and the output voltage of the solar panels were still in the range issued by the manufacturers.

Yandri [10] in a work developed a halogen based solar simulator. The simulator came up with two main parts - a structure to support PV module and the halogen light source. In order to reduce interference of light from outside hitting the surface of the tested objects, the examined PV module was placed facing down to the source of light. The results showed that intensity of light reflected by a halogen lamp was maximum toward the center of a perpendicular surface and become non-uniform to the edge of the surface. The optimal distance between source of light of the simulator and the tested module was $32 \mathrm{~cm}$, giving a maximum uniformity of $9.7 \%$. This value was still within the limits recommended by the British Standards for solar simulator experiments.

Literature showed that many researches have been conducted on solar simulators. However, it was found that the designs required improvements to address the needs of PV modules' characterization specifically for dust impact testing. As the dust material attaching to the surface of a PV module is removed easily during experiments, the PV module's position inside the solar simulator should be kept to face upwards. Another thing is that the previous solar simulators were not equipped with proper cover to avoid the intervention of light from outside.

This study aimed to develop a solar simulator dedicated for PV modules characteristics testing including those contaminated with dust. The developed solar simulator deploying halogen lamps connected in parallel as a source of light.

\section{Experimental methodology}

Solar simulator developed in this study referred to the work of Yandri [10]. The equipment applied halogen lamps connected in parallel and supplied by a 220 volts electric source. To allow the simulator to be used for dusty PV testing, the lamps were mounted on the top of the simulator and facing down, while the PV module support was located on the bottom and facing up. In addition, all four sides of the simulator were covered so that there was no outside light intervention. The design and the appearance of the developed simulator are shown in Fig. 1.

Characteristic of the light produced by the lamps and received by PV module was tested at various distance. The test results were used as a reference for PV performance investigation. Electrical specification of the examined PV module is depicted in Table 1. Current, voltage, and power output were the parameters recorded for PV performance assessment. Electrical circuit of the PV performance test is shown in Fig. 2. In addition to the indoor measurement, PV performance was also investigated outdoor by exposing the module to the sunlight. The test diagram is shown in Fig. 3. Electrical parameter values obtained both inside and outside experiments were then plotted to illustrate I-V and P-V curves of the PV module.

To find out how similar the light of solar simulator and sunlight were, the results of indoor and outdoor PV performance measurements were compared. The comparison was 
carried out after the values of the electrical parameters of the PV module recorded in both measurement conditions were converted to standard condition using the following equations [11]:

$$
\begin{aligned}
& I_{2}=I_{1}+I_{g c 1} \cdot\left(\frac{G_{2}}{G_{1}}-1\right)+\alpha \cdot\left(T_{2}-T_{1}\right) \\
& V_{2}=V_{1}-R_{g} \cdot\left(I_{2}-I_{1}\right)-\kappa_{*} \cdot I_{2} \cdot\left(T_{2}-T_{1}\right)+\beta \cdot\left(T_{2}-T_{1}\right)
\end{aligned}
$$

where, subscript 1 and 2: real operating condition (ROC) and standard test condition (STC) values respectively; I and V: current (A) and voltage (V), respectively of I-V characteristic data pairs; G: in-plane irradiance $\left(\mathrm{W} / \mathrm{m}^{2}\right) ; \mathrm{T}$ : module back side temperature $\left({ }^{\circ} \mathrm{C}\right) ; \alpha$ : current temperature coefficient $\left(\mathrm{A} /{ }^{\circ} \mathrm{C}\right) ; \beta$ : voltage temperature coefficient $\left(\mathrm{V} /{ }^{\circ} \mathrm{C}\right) ; \mathrm{R}_{\mathrm{S}}$ : the internal series resistance of the test specimen $(\Omega) ; \kappa$ : curve correction factor $\left(\Omega /{ }^{\circ} \mathrm{C}\right) ; \mathrm{P}_{\max }$ : maximum power $(\mathrm{W})$; $\mathrm{I}_{\mathrm{sc}}$ : short circuit current $(\mathrm{A}) ; \mathrm{V}_{\mathrm{oc}}$ : open circuit voltage $(\mathrm{V})$.
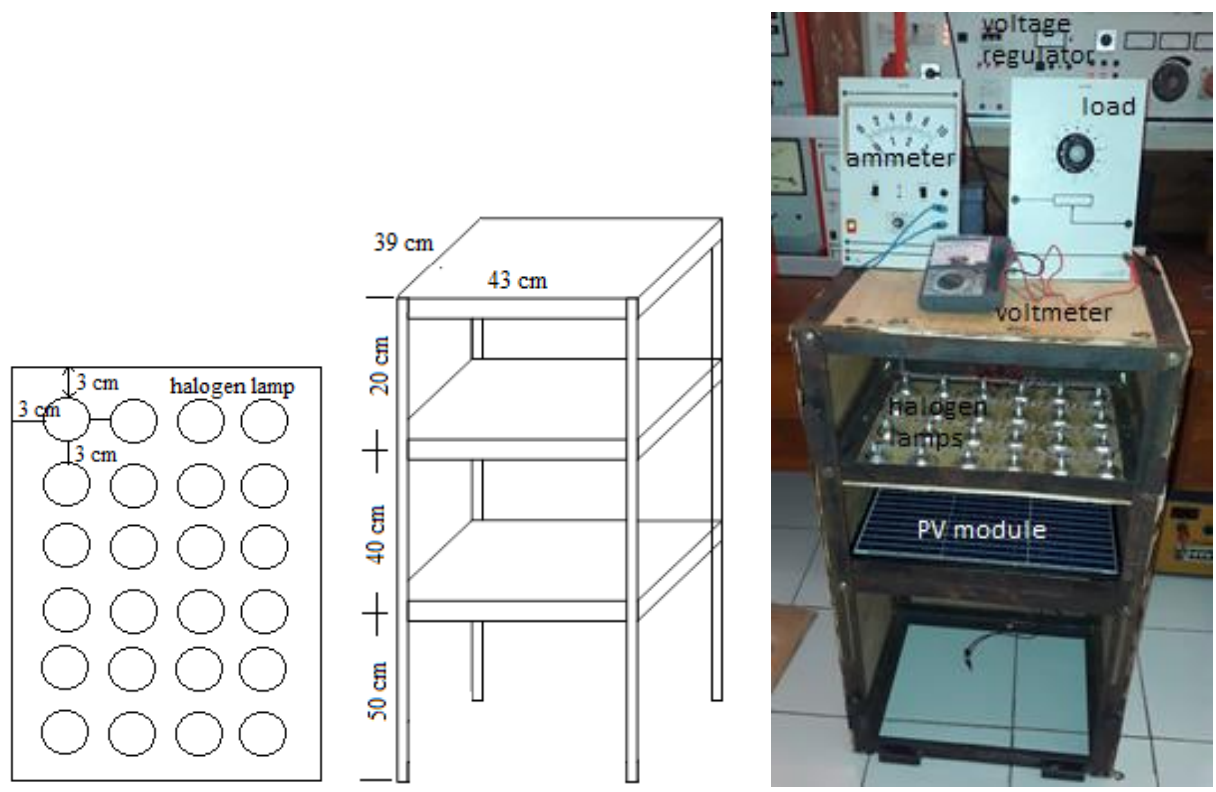

Fig. 1. Design of the solar simulator and its close-up appearance

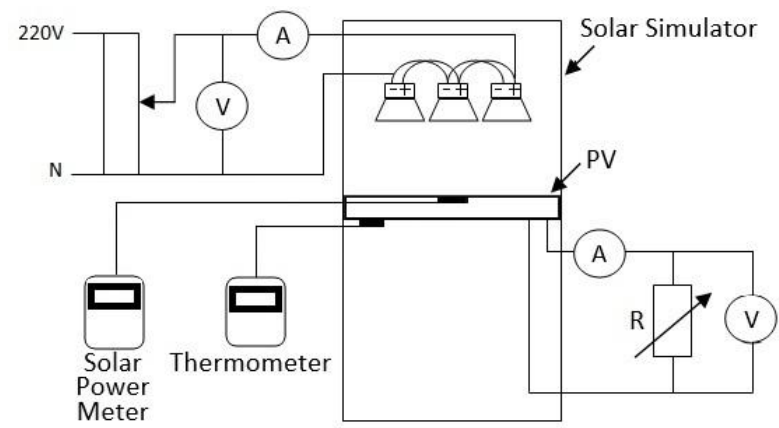

Fig. 2. Electrical circuit of indoor PV performance test 
Table 1. Technical specification of the examined solar panel

\begin{tabular}{lr}
\hline Parameters & $\mathrm{mc}-\mathrm{Si}$ \\
\hline Maximum power (Pmax) & $10 \mathrm{~W}$ \\
Voltage @ Pmax (Vmp) & $17.83 \mathrm{~V}$ \\
Current @ Pmax (Imp) & $0.56 \mathrm{~A}$ \\
Short circuit current & $0.61 \mathrm{~A}$ \\
Open circuit voltage & $21.75 \mathrm{~V}$ \\
\hline
\end{tabular}
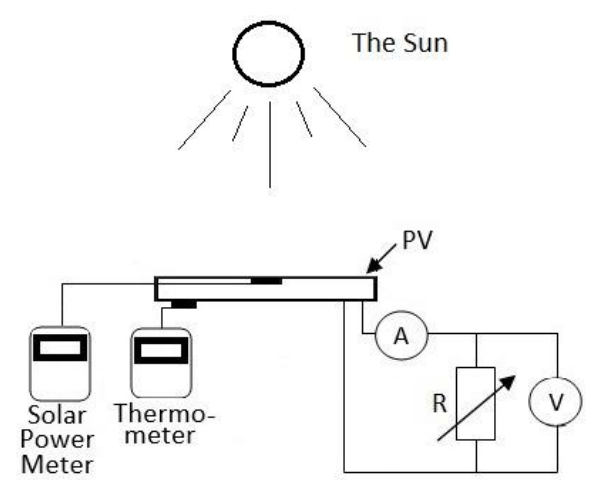

Fig. 3. Electrical circuit of outdoor PV performance test

Research methodology described in this section was summarized and depicted in Fig. 4.

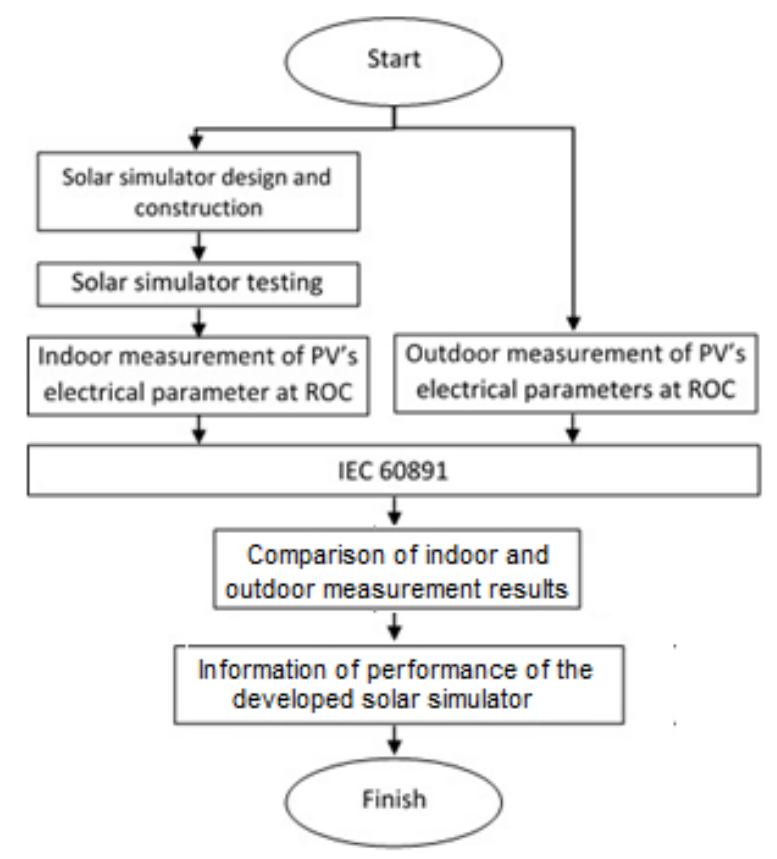

Fig. 4. Summary of the experimental methodology 


\section{Results and discussion}

\subsection{Light characteristic of the developed solar simulator}

Tests were carried out on several distance of the source of light and PV module to determine the amount of light achieving the surface of the module. The results are shown in Table 2.

Tabel 2 Light intensity measurement results based on distance

\begin{tabular}{cc}
\hline Distance $(\mathrm{cm})$ & Light intensity $\left(\mathrm{W} / \mathrm{m}^{2}\right)$ \\
\hline 4 & 1121 \\
6 & 1007 \\
9 & 938 \\
10.5 & 902 \\
12.5 & 857 \\
\hline
\end{tabular}

From these results it can be seen that the intensity of $1000 \mathrm{~W} / \mathrm{m}^{2}$ beam occurred at a distance of about $6 \mathrm{~cm}$. This value was then used to characterize the performance of the examined PV module.

\subsection{Characteristic of solar module indoor and outdoor experiments}

This section discusses the electrical parameter values of PV module investigated using solar simulator and under the Sun. Test results on various intensity and temperature conditions of indoor and outdoor measurements were then converted to the standard values. The results of the conversion are listed in Table 3.

Table 3. Conversion results of electrical parameters of the examined PV module

\begin{tabular}{rrrrrrr}
\hline & \multicolumn{3}{c}{ Sunlight } & \multicolumn{3}{c}{ Solar simulator } \\
\cline { 2 - 7 } $\mathrm{R}(\Omega)$ & $\begin{array}{r}\text { Voltage } \\
(\mathrm{V})\end{array}$ & $\begin{array}{r}\text { Current } \\
(\mathrm{A})\end{array}$ & $\begin{array}{r}\text { Power } \\
(\mathrm{W})\end{array}$ & $\begin{array}{r}\text { Voltage } \\
(\mathrm{V})\end{array}$ & $\begin{array}{r}\text { Current } \\
(\mathrm{A})\end{array}$ & $\begin{array}{r}\text { Power } \\
(\mathrm{W})\end{array}$ \\
\hline 0 & 0 & 0.67 & 0 & 0 & 0.36 & 0.00 \\
10 & 20.80 & 0.55 & 11.44 & 21.74 & 0.34 & 7.39 \\
20 & 20.82 & 0.52 & 10.83 & 21.93 & 0.29 & 6.36 \\
30 & 21.08 & 0.49 & 10.33 & 22.20 & 0.24 & 5.33 \\
40 & 21.21 & 0.45 & 9.54 & 22.31 & 0.19 & 4.24 \\
50 & 21.24 & 0.39 & 8.28 & 22.35 & 0.14 & 3.13 \\
60 & 21.41 & 0.34 & 7.28 & 22.39 & 0.09 & 2.02 \\
70 & 21.57 & 0.29 & 6.26 & 22.42 & 0.04 & 0.90 \\
80 & 21.68 & 0.24 & 5.20 & 22.44 & 0.02 & 0.45 \\
90 & 21.87 & 0.19 & 4.16 & 22.46 & 0.005 & 0.11 \\
100 & 22.03 & 0.00 & 0.00 & 22.48 & 0 & 0.00 \\
\hline
\end{tabular}

It can be seen that there are differences in the value of the measurement results on various load levels (R). At the same light intensity and temperature, the value of the solar simulator test results was smaller than the one tested under the Sun. This is caused by 
differences in the spectra of halogen lamps and sunlight. The values of I, V, and P in the Table 3 were then plotted and the result is shown in Fig. 5.

Fig. 5 shows that the maximum power output of the module exposed to the Sun is $11.44 \mathrm{~W}$ and $7.55 \mathrm{~W}$ when it was measured indoor using the simulator. Relative difference of the values was $33.9 \%(((11.44-7.55) / 11.44) \times 100)$. Based on these results, it is known that the difference in the measurement results of the maximum power output values of the solar module is $33.9 \%$. The large percentage could be attributed to the human errors and the application of non-standard measured equipment. Therefore, further research is needed to address the problem.

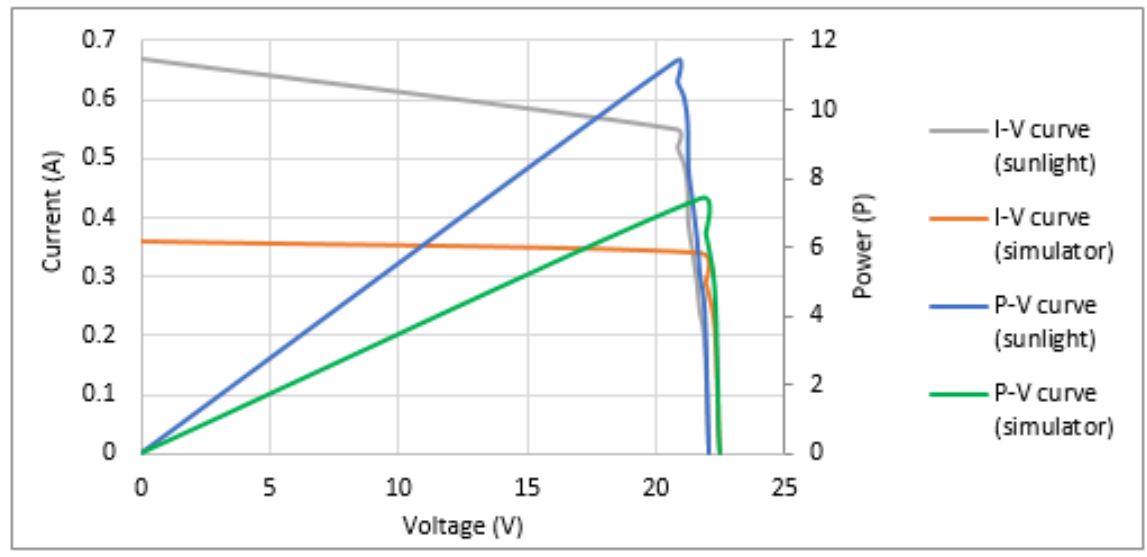

Fig. 5. I-V and P-V curves of the examined PV module

\section{Conclusion}

This study reported results of solar simulator designed for testing characteristics of PV modules including those contaminated with dust. Test results showed that the solar simulator worked well. Voltage input and distance of halogen lamp as the light source can be adjusted to produce various light intensities received by the examined PV module. Relative difference of maximum power output (Pmax) of an examined PV module measured outdoor under the Sun and indoor by deploying a solar simulator was about 33\%. The large difference was likely contributed to human errors and non-standard equipment applied during the study. Therefore, further research is needed by deploying standard equipment for more accuracy results.

\section{Acknowledgement}

The authors wish to acknowledge KEMENRISTEKDIKTI Indonesia for the financial support through the Basic Research Grant (Hibah Penelitian Dasar) with a contract number of 142/SP2HL/LT/DRPM/2019. A thank you also goes to Mr Yusuf Baitanu for his assistance during this research. 


\section{References}

[1] Namin, A., Jivacate, C., Chenvidhya, D., Kirtikara, K., \& Thongpron, J. (2012). Construction of Tungsten Halogen, Pulsed LED, and Combined Tungsten HalogenLED Solar Simulators for Solar Cell-Characterization and Electrical Parameters Determination. International Journal of Photoenergy, 2012.

[2] Chadel, M., Bouzaki, M. M., Chadel, A., Petit, P., Sawicki, J.-P., Aillerie, M., \& Benyoucef, B. (2017). Influence of the spectral distribution of light on the characteristics of photovoltaic panel. Comparison between simulation and experimental. Paper presented at the AIP Conference Proceedings.

[3] Codd, D. S., Carlson, A., Rees, J., \& Slocum, A. H. (2010). A low cost high flux solar simulator. Solar energy, 84(12), 2202-2212.

[4] Esen, V., Sağlam, Ş., \& Oral, B. (2017). Light sources of solar simulators for photovoltaic devices: A review. Renewable and Sustainable Energy Reviews, 77, 1240-1250.

[5] Klasov, A., Khvostikov, V., Khvostikova, O., Gazaryan, P., Sorokina, S., \& Andreev, V. (2007). TPV systems with solar powered tungsten emitters. Paper presented at the AIP Conference Proceedings.

[6] Guvench, M., Gurcan, C., Durgin, K., \& MacDonald, D. (2004). Solar simulator and IV measurement system for large area solar cell testing. age, 9, 1.

[7] Emery, K. (1986). Solar simulators and I-V measurement methods. solar cells, 18(3-4), 251-260.

[8] Grandi, G., Ienina, A., \& Bardhi, M. (2014). Effective low-cost hybrid LED-halogen solar simulator. IEEE Transactions on Industry Applications, 50(5), 3055-3064.

[9] Salam, R. A., Munir, M. M., Warsahemas, T., Saputra, C., Latief, H., \& Khairurrijal, K. (2019). A simple solar simulator with highly stable controlled irradiance for solar panel characterization. Measurement and Control, 52(3-4), 159-168.

[10] Yandri, E. (2018). Uniformity characteristic and calibration of simple low cost compact halogen solar simulator for indoor experiments. International Journal of Low-Carbon Technologies, 13(3), 218-230.

[11] IEC-Standard-60891. (2009). International Electrotechnical Commission. 